\title{
A REGULAÇÃO ECONÔMICA E O DIREITO DE PROPRIEDADE: NORMAS PROMOCIONAIS DE ACESSO E PERMANÊNCIA DAS MICRO E PEQUENAS EMPRESAS NO MERCADO
}

\section{THE ECONOMIC REGULATION AND PROPERTY RIGHTS: PROMOTIONAL RULES OF ACCESS AND REMAINING OF MICROENTERPRISE AND SMALL BUSINESS IN THE MARKET}

\author{
Philippe Antônio Azedo Monteiro ${ }^{1}$ \\ Marlene Kempfer ${ }^{2}$
}

\section{RESUMO}

O presente estudo aborda a intervenção do Estado por meio de normas promocionais, capazes de propiciar um ambiente de encorajamento para que micro e pequenos empresários ingressem e permaneçam no mercado econômico. Oportunizar a regularização dos ativos é o caminho para resgatar o capital morto que está na informalidade. Neste contexto destaca-se as medidas da Lei Complementar 123/2006, que originou um sistema federativo para inclusão e fomento de micro e pequenos empreendimentos. Unir a competência da intervenção estatal, por meio de normas promocionais e as potencialidades dos direitos da propriedade podem contribuir para a efetividade da referida lei.

Palavras-chave: Regulação, Microempresas, Informalidade

\begin{abstract}
This study covers the state intervention through promotional standards, capable of providing an encouraging environment for micro and small business owners from joining and remaining in the economic market. Create opportunities for regularization of assets is the way to rescue the informal dead capital. In this context it highlights the measures of Complementary Law 123/2006, which resulted in a federal system for inclusion and promotion of micro and small entrepreneurs. Uniting the competence of state intervention, through promotional standards and the property rights potential can contribute to the effectiveness of the law.
\end{abstract}

Keywords: Regulation, Microenterprises, Informality

\footnotetext{
${ }^{1}$ Mestre pelo programa de Mestrado em Direito Negocial da UEL, Universidade Estadual de Londrina - PA, Brasil. E-mail: indexlaw.ojs@hotmail.com

${ }^{2}$ Doutorado em Direito do Estado pela Pontifícia Universidade Católica de São Paulo/PUC - SP, Brasil.

E-mail: indexlaw.ojs @ hotmail.com
} 


\section{INTRODUÇÃOO}

O presente estudo de natureza bibliográfica se propõe a analisar os mecanismos trazidos pelo Estatuto Nacional da Microempresa e da Empresa de Pequeno Porte, Lei Complementar 123/2006, e identificar a intervenção do Estado sobre o domínio econômico, nos termos dos Artigos 174 e 170, IX, CF/88, a fim de distinguir as medidas com a finalidade de promover acesso e permanência no mercado.

A competência da intervenção por meio de incentivos previstos na Lei Complementar 123/2006, remete ao estudo sobre a teoria das normas promocionais apresentadas por Norberto Bobbio (2007), ao defender que o estímulo promove encorajamento e, assim, a efetividade social do ordenamento jurídico. Esta alternativa difere do tradicional caminho jurídico das normas punitivas, que nem sempre alcançam, com a rapidez desejada, que os seus destinatários se comportem conforme a ordem vigente

Associada à categoria das normas promocionais o estudo envolve, também, as ideias desenvolvidas por Hernando Soto, na obra Mistério do Capital (2001), ao se debruçar sobre a constatação de que as externalidades positivas do capitalismo, experimentadas nos países desenvolvidos, não foi alcançado nos países em desenvolvimento. Aponta, entre tantas considerações, que no âmbito da informalidade existe um capital morto que fica à margem da legalidade, e, embora faça parte da economia, seus titulares não têm as mesmas oportunidades daqueles que também estão no mercado, mas integram a redoma da legalidade. Esta força econômica pode ser resgata pelo Estado por meio de acesso aos atributos da propriedade material e imaterial, permitindo a inclusão e a permanência no domínio econômico.

Neste sentido a intervenção do Estado ocorreu no Brasil quando foi aprovado o Estatuto Nacional da Microempresa e Empresa de Pequeno Porte, Lei Complementar 123/2006. O seu texto reúne um conjunto normativo que nasce da competência prevista nos Artigos 170, IX, 174 e 179 da CF/88. Criou-se um sistema federativo em que predominam normas do nível de normas gerais, uniformizando o tratamento para esta categoria empresarial. A partir do texto normativo em análise é possível apontar inúmeras normas promocionais de natureza tributária, creditícia, administrativa, previdenciária e de oportunidades em negócios públicos.

As oportunidades introduzidas pela LC 123/2006 serão pontualmente analisados para se concluir se as normas vigentes contribuem para a efetividade ou não do objetivo de estimular o acesso e a permanência dos micro e pequenos empreendedores no mercado interno. 


\section{A INTERVENÇÃO DO ESTADO SOBRE O DOMÍNIO ECONÔMICO EM PRÓL DA INCLUSÃO ECONÔMICA}

Até o início do século XIX, prevaleciam os ideais liberais, que pregavam a existência de uma "ordem natural" na economia e que a presença do Estado deveria ser restrita à função de produção do Direito e de segurança.

Na passagem para o século XX, defendeu-se uma maior intervenção do Estado em face da constatação das imperfeições do liberalismo clássico, ante o aumento de monopólios, de cíclicas crises econômicas e de domínio do poder econômico, que suprimia a concorrência saudável, imaginada na ideia inicial de mão invisível do mercado. Portanto, passou-se a defender a atuação do Estado sobre o domínio econômico. (GRAU, 2012, p.18-30)

A calculabilidade e a confiança na eficácia da ordem jurídica constituem exigências vitais ao capitalismo, pois este sistema depende de estabilidade, previsibilidade e segurança jurídica. Tal ambiente é esperado a partir das competências que foram atribuídas ao Estado tanto para produzir regras (centralização do poder político) quanto pela função jurisdicional, na medida em que foi proibida a autotutela. (GRAU, 2012, p.3136)

Desde que se verificou a institucionalização de órgãos com a função de aplicar o direito objetivo na controvérsia de interesses e desde que um fato ou ato produziram consequências normativas (direitos e deveres jurídicos), os particulares perderam o poder de fazer valer por si próprios o direito controvertido, esse poder foi avocado pelo Estado e os particulares adquiriram o direito de exigir a prestação jurisdicional ante esse órgão. (VILANOVA, 2003, p.467)

O Estado poderá intervir no e sobre o domínio econômico, nos seguintes termos: a intervenção por absorção ou participação; por direção; e, por indução. Na intervenção por absorção ou por participação, o Estado intervém no domínio econômico, isto é, no campo da atividade econômica, desenvolve a ação como agente econômico. Quando o faz por absorção, o Estado assume integralmente o controle dos meios de produção e/ou atua em regime de monopólio em determinado setor da atividade econômica. Quando o faz por participação, o Estado assume o controle de parte dos meios de produção em determinado setor, atuando em regime de competição com empresas privadas que permanecem a exercer suas atividades nesse setor. Outra opção é intervir sobre o domínio econômico, 
isto é, desenvolver sua ação como regulador da atividade. Quando o faz por direção, o Estado estabelece normas e mecanismos para os sujeitos de determinada atividade econômica. E quando o faz por indução, o Estado manipula os instrumentos legais a fim de estimular ou inibir determinado comportamento. (GRAU, 2012, p.143)

Interessa ao presente estudo a intervenção do Estado sobre o domínio econômico por meio das normas de direção e de indução. No caso das normas de intervenção por direção, há comandos imperativos, dotados de força prescritiva de certos comportamentos a serem necessariamente cumpridos pelos agentes que atuam no campo da atividade econômica. No caso das normas de intervenção por indução, há preceitos que, embora prescritivos, não são dotados da mesma carga de impositiva que afeta as normas de intervenção por direção. Nelas, a sanção, tradicionalmente manifestada como um comando, é substituída pelo expediente do convite, do estímulo e dos incentivos oferecidos pela lei a quem participe de determinada atividade de interesse público. Ao destinatário da norma resta aberta a alternativa de participar ou não da prescrição nela veiculada. Esse é o universo do Direito premial, pois, ao manifestar a adesão, o destinatário da norma estará juridicamente vinculado àquela prescrição de benefícios dispostos na lei. (GRAU, 2012, p.144-145).

Norberto Bobbio, na obra Da estrutura à função (2007), parte de uma análise da teoria geral do direito e se aprofunda nos estudos sobre controle social para sustentar o emprego de técnicas de encorajamento em detrimento das usuais técnicas de punição e desencorajamento.

O modelo de Estado protetor pautado em comandos repressivos e proibições dá lugar ao emprego das técnicas de encorajamento. Por meio delas tende-se a abandonar a visão tradicional do Direito como ordenamento protetor-repressivo e adotar a forma de um ordenamento jurídico com função promocional, de modo que, ao lado da função de tutela ou garantia, aparece, cada vez com maior frequência, a função de promover. A técnica de encorajamento visa não apenas tutelar, mas, também, provocar o exercício dos atos conformes, atos permitidos, com a possibilidade de fazer e a possibilidade de não fazer. $\mathrm{A}$ introdução do encorajamento reflete uma transformação na função do sistema normativo em seu todo e no modo de realizar o controle social. Além disso, assinala a passagem de um controle passivo - mais preocupado em desfavorecer as ações nocivas do que em 
favorecer as vantajosas - para um controle ativo - preocupado em favorecer as ações vantajosas mais do que em desfavorecer as nocivas. (BOBBIO, 2007, p.13-15)

O encorajamento se dá intervindo sobre as consequências do comportamento ou sobre as condições do próprio comportamento. Existe a facilitação - o caso de uma ajuda ou de uma contribuição financeira, ou mesmo de uma facilitação de crédito - e o da sanção positiva, como a consignação de um prêmio para um comportamento ou de uma isenção fiscal. As normas de desencorajamento são usadas predominantemente com o objetivo de conservação social e as de encorajamento com o objetivo de mudança. Uma atribui valor à inércia, ao fato de as coisas permanecerem como estão, enquanto a outra valoriza a transformação. (BOBBIO, 2007, p.19)

Ao se recortar o estudo sobre as normas voltadas às micro e pequenas empresas, na Lei Complementar 123/2006, aponta-se a intervenção por direção e indução tratadas por Eros Graus e as promocionais assim denominadas por Bobbio. O objetivo é promover o encorajamento daqueles que têm interesse em compor o âmbito econômico por uma atividade empresarial.

A Ordem Econômica da Constituição de 1988 revela uma opção jurídica pela orientação da economia, afastando a ideia do Estado como ator pontual das relações econômicas. Há competências para a participação do Estado na promoção de políticas de desenvolvimento, por intermédio das quais define diretrizes e políticas públicas capazes de estabelecer uma "economia planificada", impondo a salvaguarda de fatores que assegurariam uma relação de mercado sustentável a longo prazo. (DERANI 2008, p.197),

Esta atuação regulatória em um Estado Democrático de Direito se justifica desde que se promova possibilidades para a convivência em ambiente de justiça social (Art. 170, caput, da $\mathrm{CF} / 88$ ), que poderá ser real quando houver mais inclusão e permanência de agentes econômicos no mercado.

\section{0 (IN)SUCESSO DO CAPITALISMO NOS ESTADOS EM DESENVOLVIMENTO NOS TERMOS DE HERNANDO DE SOTO}

A importância da atuação e da regulação do Estado em interferir na ordem econômica para viabilizar o acesso e a permanência dos pequenos empresários no mercado, e para facilitar a regularização de suas propriedades, é evidenciada por Hernando de Soto, na obra O Mistério do Capital (2001). O livro se originou de pesquisas realizadas em países não desenvolvidos, e concluiu que estas nações não experimentam o capitalismo como as nações 
mais desenvolvidas, pois os contratos sociais informais obstam a transformação de seus ativos em capital.

O capital é a força motriz da produtividade e da geração de riqueza, todavia, países como o Brasil não usufruem desse potencial, pois a burocracia e a informalidade impedem de avançar no aproveitamento do capital. As posses são defectivas, as casas são construídas em terras cujos direitos de propriedade não estão adequadamente registrados, as empresas são erigidas sem a observância legal e as indústrias não alcançam investidores, pois a grande parcela da sociedade das nações menos desenvolvidas está imersa em uma teia de informalidade cuja validade e o aceite estão restritos ao estrito a um raio local.

Os direitos de propriedade não são adequadamente documentados, por isso, esses ativos (casas, quotas e bens) não podem se transformar de pronto em capital, eles não conseguem ser trocados fora dos estreitos círculos locais onde as pessoas se conhecem e confiam umas nas outras, ou seja, não são aceitos como garantia a empréstimos e participação em investimentos.

Nos países desenvolvidos, por sua vez, toda parcela de terra, toda construção, todo equipamento ou estoque está representado por um documento de propriedade, o sinal visível de um vasto processo oculto conectando todos esses ativos ao restante da economia. Graças a esse processo de representação, os ativos podem levar uma vida invisível, paralela à sua existência material. Podem ser usados como garantia na obtenção de crédito. (SOTO, 2001, p.21)

O sistema formal de propriedade processa ativos em capital descrevendo e organizando os aspectos mais úteis econômica e socialmente sobre eles, preservando essa informação em um sistema de registros e, depois, incorporando-os em um título. Registros de propriedade e os títulos representam um conceito compartilhado do que é economicamente significativo sobre qualquer ativo. Capturam e organizam toda a informação relevante e necessária na conceituação do valor potencial de um ativo. A propriedade é o domínio onde se identifica e explora os ativos, se combina ou uni a outros ativos. (SOTO, 2001, p.60)

A representação formal de uma propriedade não funciona apenas de garantia na transformação de um ativo em capital, mas, num contexto social, serve como um meio de assegurar os interesses de terceiros e de promover a responsabilidade do seu proprietário, proporcionando as informações, as referências e os mecanismos de execução necessários 
para isso. Quando a cadeia registral opera regularmente, a propriedade formal pode ser utilizada como garantia em empréstimos; como endereço na cobrança de impostos, taxas e dívidas; na localização que identifica os indivíduos para motivos comerciais, judiciais ou cívicos; ou como terminal responsável para o recebimento de serviços públicos tais como energia, água, esgoto, telefone ou TV. A propriedade legal concedeu aos países desenvolvidos as ferramentas para produzir um valor que vai além e acima de seus ativos físicos.

As pessoas dos países em desenvolvimento, todavia, não conseguem adentrar o sistema legal de propriedade porque não podem inserir seus ativos, e acabam por possuílos de forma extralegal. Para Soto (2001, p.66) a grande diferença entre as nações desenvolvidas e as em desenvolvimento reside na integração dos ativos a um sistema de representação formal. As nações desenvolvidas integraram em um único sistema compreensível todos os dados em um banco de dados amplo, confiável e transparente.

As representações também permitem a divisão dos ativos sem ser preciso tocá-los. Enquanto um ativo tal como uma fábrica pode ser uma unidade indivisível no mundo real, no universo conceitual da representação de propriedade formal pode ser subdividida em porções de qualquer número. Aqueles que possuem formal regularidade de seus ativos são, portanto, capazes de dividi-los em ações, e cada qual pode ser propriedade de pessoas diferentes, com direitos diferentes, para desempenhar funções diferentes. Graças à propriedade formal, uma única fábrica pode ser mantida por inúmeros investidores, e que podem até se livrar de suas propriedades sem afetar a integridade do ativo físico.

Os sistemas de propriedade, assim como as redes de computadores, exploram o efetivo potencial existente quando interligados em uma rede mais ampla. Só então o potencial de um direito de propriedade pode ser explorado. Muitos dos problemas dos mercados encontrados nos países em desenvolvimento se devem à fragmentação dos acordos de propriedade e à indisponibilidade de normas padronizadas aos ativos e agentes econômicos para interagirem. (SOTO, 2001, p.88-89)

Nas nações menos desenvolvidas faltam instituições que integrem os informais no setor formal, que fixem seus ativos em formas fungíveis, e que forcem seus donos a serem agentes responsáveis, lhes proporcionando dispositivos de integração, permitindo que se enfrentem produtivamente e gerem capital dentro de um amplo mercado legal. Do contrário, os informais são forçados a inventar, à custa da ordem legal, uma série de 
acordos extralegais para substituir as leis e as instituições de que precisam e então cooperarem em um mercado alternativo. (SOTO, 2001, p.89-90)

Por este motivo, Hernando de Soto (2001, p.112) sustenta a necessidade de a lei oficial alcançar a realidade do impulso extralegal concedendo o devido direito de propriedade aos que estão na informalidade e na extralegalidade.

O reconhecimento do direito de propriedade é fundamental ao modelo social atual, pois, o uso do bem em todo o seu potencial decorre necessariamente do reconhecimento social que relaciona a propriedade ao seu proprietário.

A descrição da propriedade e o reconhecimento dos direitos de um determinado bem ao seu detentor tem origem na revolução francesa e, desde então, a discussão tem evoluído a fim de ir além da mera relação entre a pessoa e a coisa, mas de estabelecer as formas e os limites no seu uso. Porém, a maioria dos direitos relacionados ao patrimônio se esvazia se o bem não estiver devidamente relacionado a seu dono, ou seja, se o bem não estiver relacionado ao seu regular proprietário segundo lógica de registro adotada na sociedade moderna.

Na Código Civil brasileiro, Lei 10.406/2002, a propriedade e os direitos dela decorrentes dependem do registro do título, ou seja, a propriedade é considerada e transmitida, para fins legais, através do registro do título no Registro de Imóveis, nos termos do Art. 1.227 do $\mathrm{CC} / 02$

O Art. 1.238 do CC/02, todavia, elenca outras formas de aquisição da propriedade, tal qual a aquisição por usucapião, ocasião em que o Código reconhece o direito daquele possuidor

de boa-fé. Os institutos do registro e da usucapião estão intimamente relacionados, pois, a usucapião, na realidade, não passa de uma medida para transformação de uma realidade fática em jurídica, ou seja, é o pedido de reconhecimento e registro daquele bem em nome do seu possuidor, o que corroborando ainda mais a importância do registro e da formalização dos ativos para que estes existam no universo jurídico e deles se possa extrair todo o potencial dos ativos, permitido, segundo as regras da sociedade capitalista, sua transformação em capital.

A ideia de a lei estimular a formalização daqueles que estão na extralegalidade, seja por mecanismos de acesso, de estímulo e de regularização das atividades daqueles atuam à margem das prescrições legais é o objetivo da Lei Complementar 123/2006, denominado Estatuto da Microempresa, que em seu bojo traz normas para estimular a formalização, o acesso e o crescimento das atividades de micro e pequeno porte. 


\section{NORMAS QUE POSSIBILITAM O ACESSO AO MERCADO NOS TERMOS DA}

\section{LC 123/2006}

O presente estudo se propôs a distinguir as medidas de acesso, daquelas medidas que influem a permanência dos pequenos negócios no mercado. Antes de adentrar especificamente cada uma das medidas implementadas pela LC 123/2006, oportuno destacar que os destinatários do Estatuto Nacional da Microempresa são, nos termos do art. $3^{\circ}$ : as sociedades empresárias, as sociedades simples, os Microempreendedores Individuais (MEI) e as Empresas Individuais de Responsabilidade Limitada (EIRELI). ${ }^{1}$

A primeira medida de acesso a ser aqui abordada é a da simplificação registral. Acredita-se ser um bom estímulo para a formalização daqueles que não conseguem vencer a burocracia (controles públicos) e sair da informalidade. Por isso, o Estatuto Nacional da Microempresa, LC 123/2006, previu a implementação de um procedimento unificado para regularização da atividade empresarial, seja no âmbito federal, estadual ou municipal. Regularizar a atividade empresarial é uma das formas de regularização dos ativos, como tratado na obra de Hernando de Soto (2001). Obtendo um CNPJ, torna-se possível abrir conta, filial, contratar, vender, emitir

\footnotetext{
${ }^{1}$ Art. $3^{\circ}$ Para os efeitos desta Lei Complementar, consideram-se microempresas ou empresas de pequeno porte, a sociedade empresária, a sociedade simples, a empresa individual de responsabilidade limitada e o empresário a que se refere o art. 966 da Lei no 10.406, de 10 de janeiro de 2002 (Código Civil), devidamente registrados no Registro de Empresas Mercantis ou no Registro Civil de Pessoas Jurídicas, conforme o caso, desde que: I - no caso da microempresa, aufira, em cada ano-calendário, receita bruta igual ou inferior a $\mathrm{R} \$$ 360.000,00 (trezentos e sessenta mil reais); e II - no caso da empresa de pequeno porte, aufira, em cada anocalendário, receita bruta superior a $\mathrm{R} \$ 360.000,00$ (trezentos e sessenta mil reais) e igual ou inferior a $\mathrm{R} \$$ 3.600.000,00 (três milhões e seiscentos mil reais).
}

notas e tantas outras benesses somente alcançáveis àqueles que estão inseridos na formalidade. A importância dessa formalização é tamanha que, todas as demais medidas disciplinadas na LC 123/2006, dependem de que o empresário inicialmente esteja formalizado. Sem a regularização sequer se pode acessar os demais benefícios tratados no Estatuto Nacional da Microempresa.

As disposições do art. $4^{\circ}$ da LC $123 / 2006^{2}$ deverão ser adotados pelas diversas entidades e órgãos responsáveis pelo processo de abertura ou fechamento de empresas, de forma a garantir a existência de providências integradas e lineares, sem se permitir a duplicidade de exigências, de maneira que seja assegurado ao interessado que ele está 
diante de um único processo, mesmo que nos órgãos ocorram mais de um processo de regularização.

A unicidade de procedimento inclui todos os órgãos que tenham como incumbência a abertura, regularização, registros, alvarás, licenças e outras providências indispensáveis para o funcionamento regular da empresa de pequeno porte. Para esse efeito será assegurado ao micro e pequeno empresário a facilidade de ingressar com seus dados cadastrais num único local, gerando, no entanto, efeitos perante todos os órgãos competentes para a regularização de seu funcionamento. A entrada de documentos e requerimentos será unificada, sem que isso signifique a unificação dos órgãos, mas tãosomente a unificação do protocolo de recebimento de documentos, requerimentos e informações, de modo que cada órgão deverá manter sua base de dados de forma isolada e independente. (MARINS, 2007, p.48-49)

A LC 123/2006 deixa claro que não poderão ser impostas barreiras para a abertura e arquivamento dos atos societários de micro e pequenos empresários, seja qual for a providência exigida pelos três âmbitos de governo (federal, estadual ou municipal). Somente será imposta ao microempresário ou empresário de pequeno porte se tiver relação direta e lógica com o ato de registro, alteração ou baixa da empresa e sua consequente criação, alteração ou extinção. (MARINS, 2007, p.64)

Outra medida trazida pela Estatuto Nacional da Microempresa, LC 123/2006, e que se enquadra como benefício de estímulo ao acesso ao mercado, é o Simples Nacional, um regime especial de tributação por estimação objetiva, que unifica a fiscalização, o lançamento e a arrecadação de determinados impostos e contribuições de competência de todos os entes, União, Estados, Municípios e Distrito Federal, e é opcional aos beneficiários da Lei, com o escopo de

\footnotetext{
${ }^{2}$ Art. $4^{\circ} \mathrm{Na}$ elaboração de normas de sua competência, os órgãos e entidades envolvidos na abertura e fechamento de empresas, dos 3 (três) âmbitos de governo, deverão considerar a unicidade do processo de registro e de legalização de empresários e de pessoas jurídicas, para tanto devendo articular as competências próprias com aquelas dos demais membros, e buscar, em conjunto, compatibilizar e integrar procedimentos, de modo a evitar a duplicidade de exigências e garantir a linearidade do processo, da perspectiva do usuário.

atribuir a esses contribuintes um tratamento fiscal diferenciado e favorecido, em caráter parcialmente substitutivo ao regime geral e compulsório. (MARINS, 2007, p.68)

O Simples Nacional é um regime tributário especial porque excepciona parcialmente a regra, criando um regime jurídico diferenciado e favorecido, e, assim, é especial, pelo escopo
} 
de tornar eficaz no terreno fiscal, o princípio constitucional do tratamento jurídico diferenciado e favorecido à microempresas e empresas de pequeno porte, nos termos do Art. $179 \mathrm{da} \mathrm{CF} / 88$.

O Simples Nacional tem por base três características funcionais: a periodicidade mensal; a unificação documental; e a abrangência limitada a determinados tributos. A Lei detalhou quais seriam os tributos abrangidos, deixando uma estreita margem para a regulamentação infralegal. E os tributos abrangidos são: Imposto sobre a Renda da Pessoa Jurídica (IRPJ); Imposto sobre Produtos Industrializados (IPI); Contribuição para o Financiamento da Seguridade Social (COFINS); Contribuição Social sobre o Lucro Líquido (CSLL); Contribuição para o Pis/Pasep; Contribuição para a Seguridade Social; Imposto sobre Circulação de Mercadorias e Serviços (ICMS); e Imposto sobre Serviços de Qualquer Natureza (ISS).

O regime especial do Simples Nacional não substitui a totalidade do sistema geral, uma vez que é aplicável somente aos impostos e contribuições expressamente listados na lei. Assim, apenas alguns impostos foram abarcados pelo regime. Sendo o caso de incidir um imposto não incluído pelo Simples Nacional sobre determinada atividade, não desonera a empresa de recolhê-los na forma do sistema geral.

O Simples Nacional é uma significativa medida de acesso ao mercado, pois a opção pelo regime tributário comum ou especial é feito nos primeiros atos de constituição da atividade, e, também, porque implica em facilidade no atuar cotidiano do empresário. Isso não significa que a situação seja imutável. Ela não é. Tanto aqueles que estão no regime comum podem migrar para o regime especial, como os que estão no regime especial podem ir para o regime tributário regular, desde que enquadradas como beneficiárias da lei, não violadas as exceções da LC 123/2006, e, ainda, respeitadas as características do instituto, que são: facultatividade, anualidade e irretratabilidade para o ano-calendário.

Por meio da facultatividade tem-se que os beneficiários da LC 123/2006 podem optar pelo regime tributário comum ou pelo regime especial do Simples Nacional. Anualidade, significa que essa opção precisa durar todo um ano calendário, assim, fazendo-se a opção por determinado regime tributário, não se pode alterá-lo até o encerramento do ano-calendário. Isso remete à terceira característica, a irretratabilidade para o ano calendário, ou seja, o empresário não está obrigado a aderir ao regime tributário especial, nem nele permanecer, mas, ao aderir, seja no ato de formalização da atividade ou na mudança de regime, é preciso 
permanecer no regime escolhido durante todo o exercício, isto é, não é permitido alternar o regime no curso do exercício do ano calendário.

A simplificação registral e o Simples Nacional foram aqui consideradas como medidas de acesso ao mercado, um conjunto de normas encorajadores de conteúdo administrativo e tributário, que facilitou a adesão ao regime por meio de cadastro unificado para obtenção de licenças para a atividades econômicas que dependem do exercício do poder de polícia e, no âmbito tributário, a unificação de arrecadação, diminuindo os inúmeros deveres instrumentais próprios do regime tributário tradicional aplicável as outras empresas.

\section{MEDIDAS DE PERMANÊNCIA NO MERCADO NOS TERMOS DA LC 123/2006}

Além das medidas que contribuem para o acesso do empresário à formalidade, há, no Estatuto Nacional da Microempresa, também, normas que contribuem para a sua permanência no mercado econômico. Sob essa ótica, há a previsão de oferta de crédito público, tratamento especial para participar nas licitações e assim realizar negócio com o poder público, preferência na contratação com empresas regionais, formação de consórcios para serviços de segurança e medicina do trabalho, simplificações de obrigações no âmbito das relações do trabalho e, ainda, a dupla fiscalização.

Quanto às normas que regulamentam a licitação, a LC 123/06, trouxe modificações na Lei 8.666/1993, tanto na fase de habilitação quanto de classificação, ou seja, as mudanças se operaram na fase inicial de habilitação e na classificatória.

Em toda licitação, a seleção do vencedor resulta da avaliação de requisitos relacionadas a idoneidade do sujeito e a proposta propriamente dita. As duas questões inter-relacionam-se, já que os requisitos da idoneidade podem afetar a condição para executar a proposta. A LC 123/2006 assegurou às pequenas empresas um benefício específico relativo ao momento da habilitação: um regime próprio para a regularidade fazendária.

O benefício não reside na dispensa de apresentação de documentos de regularidade fiscal, nem se trata de dilação quanto à oportunidade própria para a exibição dos documentos. O que se faculta é a desnecessidade de perfeita e completa regularidade fiscal no momento da abertura ou do julgamento do certame. Em outras palavras, o benefício outorgado às pequenas empresas, no âmbito da habilitação, trata-se da faculdade de 
regularização de defeitos existentes e comprovados nos documentos de regularidade fiscal apresentados no momento oportuno pela micro ou pequena empresa. (JUSTEN FILHO, 2007, p.67)

A LC 123/2006 foi devidamente clara ao dispor que as empresas beneficiárias não estão dispensadas de apresentar a documentação exigida. Deverão apresentar toda a documentação, mesmo que haja alguma restrição fiscal. E acaso essa empresa seja declarada a vencedora do certame, será assegurado o prazo de 5 (cinco) dias úteis, para a regularização da documentação, pagamento ou parcelamento do débito e emissão de eventuais certidões negativas ou positivas com efeito de certidão negativa, prazo esse prorrogável por igual período, a critério da administração pública.

$\mathrm{Na}$ fase classificatória, a lei contempla como critério de desempate a preferência na contratação de micro e pequenas empresas em relação às suas concorrentes no procedimento licitatório, todas as vezes que a proposta apresentada pela beneficiária da LC 123/2006 for igual ou até $10 \%$ (dez por cento) superior à proposta mais bem classificada. Esse valor é reduzido a 5\% (cinco por cento) na modalidade pregão. Nessas situações, a micro ou pequena empresa terá a oportunidade de apresentar uma nova proposta a um preço inferior àquela considerada vencedora do certame. Essa é uma faculdade da microempresa e da empresa de pequeno porte, que poderá, todavia, não ter interesse em rever a proposta inicialmente apresentada. Aliás, se a melhor proposta tiver sido dada por uma micro ou pequena empresa, não há que se aplicar tal dispositivo aos demais concorrentes do certame.

E, ainda, para estimular o desenvolvimento regional, dispôs o legislador a possibilidade de, nas contratações públicas, se estabelecer a prioridade de contratação para as microempresas e empresas de pequeno porte sediadas local ou regionalmente, quando se verificar a diferença de até $10 \%$ (dez por cento) do melhor preço válido.

As normas encorajadoras que tratam de acesso ao crédito contribuem para permanência do empresário no mercado, em especial, porque há uma garantia legal de política pública federal neste sentido. A LC $123 / 2006^{3}$, no Art. 58, impôs aos bancos públicos o dever de manutenção de linhas de crédito específicas para as MEI, ME e EPP. Estabelece mecanismos de controle desta obrigação: exige que tais créditos sejam identificados nos orçamentos dos bancos e que seja dada ampla divulgação; os bancos devem apresentar relatório que mostre a alocação dos recursos de crédito, identificando os que foram utilizados e a explicação do bom ou mau desempenho da política pública. 
3 Art. 58. Os bancos comerciais públicos e os bancos múltiplos públicos com carteira comercial e a Caixa Econômica Federal manterão linhas de crédito específicas para as microempresas e para as empresas de pequeno porte, devendo o montante disponível e suas condições de acesso ser expressos nos respectivos orçamentos e amplamente divulgadas.

Relacionado ao tema, existe, o Programa Nacional de Microcrédito Produtivo Orientado

- Programa Crescer, lançado pelo governo federal, em agosto/2011, com o objetivo de facilitar as condições de financiamento, com menores taxas de juros e metas de empréstimos a serem atingidas pelos bancos públicos, oferecendo crédito de até $\mathrm{R} \$ 15 \mathrm{mil}$, com juros menores, próximos a 5\% (cinco por cento) ao ano.

Além das linhas de crédito específicas para os pequenos empresários, outro grande óbice enfrentado no setor e abordado no presente artigo reside na falta de garantias hábeis a lastrear as tomadas de crédito. Para a transformação de ativos em capital se exige regular documentação formal de um patrimônio que garanta a transação, ou seja, os bancos exigem garantias reais para a liberação de crédito. É preciso apresentar patrimônios regularmente formalizados, livres e desimpedidos para que os bancos liberem capital.

Ciente da dificuldade enfrentada pelos pequenos empresários em tomar crédito, já que não possuem ativos regularmente formalizados e capazes de lastrear as suas transações, foi criado, com fulcro na LC 123/2006, mecanismos oficiais de prestação de garantias, criando-se fundos de aval para facilitar a obtenção de crédito por micro e pequenas empresas, segundo

disposto no Art. $60-\mathrm{A}^{4}$. Ao tomar crédito, empreendedores de menor porte encontram dificuldades em atender as garantias exigidas pelas instituições financeiras, que inviabilizam a contratação do financiamento desejado, ou levam à aprovação em condições menos favoráveis. Isto se deve pela falta de ativos capazes de lastrear as transações. Assim, ao complementar as garantias oferecidas pelas empresas aumentam as chances de aprovação dos pedidos de crédito. O crédito poderá ser usado para aquisição de equipamentos, expansão de unidades produtivas, aquisição de softwares, capital de giro, entre outros. Gerar oportunidade por meio deste sistema garantidor de crédito é fundamental para a redução das barreiras enfrentadas pelos pequenos empresários na tomada de crédito.

Mais uma medida que contribui à permanência do pequeno empresário no mercado está na possibilidade de formação de consórcio para serviços de segurança e medicina do 
trabalho. A Consolidação das Leis do Trabalho (CLT) estabelece que as empresas são obrigadas a manter Serviços Especializados em Segurança e Medicina do Trabalho (SESMT). O Ministério do Trabalho, por seu turno, regulamenta essa matéria de forma detalhada por meio da chamada Norma Regulamentadora $n^{\circ} 4$ (NR-4). Referida norma determina a estrutura mínima que a

\footnotetext{
${ }^{4}$ Art. 60-A. Poderá ser instituído Sistema Nacional de Garantias de Crédito pelo Poder Executivo, com o objetivo de facilitar o acesso das microempresas e empresas de pequeno porte a crédito e demais serviços das instituições financeiras, o qual, na forma de regulamento, proporcionará a elas tratamento diferenciado, favorecido e simplificado, sem prejuízo de atendimento a outros públicos-alvo. Parágrafo único. O Sistema Nacional de Garantias de Crédito integrará o Sistema Financeiro Nacional.
}

empresa deverá ter a depender do grau de risco da atividade desenvolvida e do número de trabalhadores. Uma empresa com até 50 empregados, não precisa ter uma estrutura de Segurança e Medicina do Trabalho. Entretanto, a empresa com mais de 50 empregados e, dependendo do risco da atividade, poderá demandar uma estrutura que vai desde um técnico em segurança do trabalho até toda uma equipe composta de médico, enfermeiro, engenheiro e auxiliar de enfermagem, todos especializados em segurança e medicina do trabalho.

A LC 123/2006 trouxe um benefício aos pequenos empresários, mas sem prejudicar a estrutura da CLT, pois, tão somente, permite aos microempresários que se unam por meio de consórcios para a administração e custeio dos serviços especializados em segurança e medicina do trabalho. Assim, mesmo diante do consórcio, há de ser observada a gradação da NR-4.

As micro e pequenas empresas podem terceirizar, por meio de consórcio, os serviços especializados em segurança e medicina do trabalho. É mais uma forma de terceirização legal de serviços especializados. (ALMEIDA, 2009, p.155)

A própria NR-4 já possibilita a criação de estrutura consorciada, desde que o grau de risco seja compatível, mas pela LC 123/2006, independentemente do grau de risco da atividade do microempresário ou do número de funcionários, sempre lhe será permitido utilizar-se do consórcio com outros pequenos empresários para a diluição dos custos relativos à manutenção de tais serviços.

Outro benefício trazido pela LC 123/2006 e que influi na permanência no mercado está em relação aos deveres no âmbito das relações do trabalho como a dispensa da afixação de Quadro de Trabalho, disciplinado pelo art. 74 da CLT, cuja função é dar publicidade ao regime de jornada de trabalho a que são submetidos os funcionários. Também há dispensa com 
relação a anotação de férias no livro ou ficha de registro, que está disciplinada no $\S 2^{\circ}$ do art. 135 da CLT. Estão dispensados de empregar e matricular seus aprendizes nos cursos dos Serviços Nacionais de Aprendizagem, disciplinado no art. 429 da CLT. Os beneficiários ainda estão dispensados da obrigação do art. 628 da CLT, de possuir ou usar o livro intitulado “Inspeção do Trabalho". E sobre a concessão de férias coletivas, pelo $\S 3^{\circ}$ do art. 139 da CLT, o empregador deve comunicar o sindicato e afixar avisos nos locais de trabalho, está dispensado, entretanto, de comunicar tal fato ao Ministério do Trabalho. (MARINS, 2007, p.221)

As dispensas de algumas exigências de natureza trabalhistas podem parecer de menor importância, mas influenciam na desoneração do pequeno empresário e com medidas de facilitação e desoneração é que se constrói a efetividade do Estatuto Nacional da Microempresa.

Por fim, tem-se a regra que determina a chamada fiscalização orientadora. Esta norma protege o microempresário e o empresário de pequeno porte que inicia suas atividades

formalmente. Neste sentido há o reconhecimento de que a empresa estará mais sujeita a eventuais infrações ante o vasto número de regras existentes no ordenamento brasileiro. Sendo assim, a LC 123/2006 determinou que os órgãos de fiscalização responsáveis pelas áreas de recursos humanos, metrologia, ambiente e segurança, obrigatoriamente deverão esclarecer e orientar o micro e pequeno empresário acerca das normas a serem respeitadas e dos procedimentos corretivos a serem adotados antes de proceder a autuação.

O fiscal deverá observar o critério da dupla visita, ou seja, constatada uma irregularidade, o micro ou pequeno empresário deverá ser orientado com relação às correções a se providenciar e somente poderá ser autuado acaso, numa segunda inspeção a ser agendada pelo fiscal, com um prazo suficiente para realizar os ajustes indicados, não tenha procedido às correções determinadas.

A LC 147/2014 incluiu, dentre outras mudanças, os $\S \S 6^{\circ}, 7^{\circ}$ e $8^{\circ}$ ao artigo 55 da LC 123/2006, que dispõem ser nulo o auto de infração lavrado sem atendimento ao critério da dupla visita; que as entidades da administração pública deverão observar o princípio do tratamento diferenciado por ocasião da fixação de valores decorrentes de multas e demais sanções administrativas; e que a inobservância do disposto no caput deste artigo implica atentado aos direitos e garantias legais assegurados ao exercício profissional da atividade empresarial. $^{5}$ 
Apenas não será observado o critério de dupla visita, quando for constatada infração de natureza grave, como a falta de registro de empregado ou de anotação da Carteira de Trabalho e Previdência Social (CTPS), ou, ainda, na ocorrência de reincidência, fraude, resistência ou embaraço à fiscalização.

\section{CONCLUSÃO}

O presente estudo parte da análise das normas de regulação sobre o domínio econômico voltadas às micro e pequenas empresas. No Estatuto Nacional da Microempresa, LC 123/2006,

é possível identificar a intervenção do Estado sobre o domínio econômico, de forma normativa, nas modalidades erigidas por Eros Grau (2012) como direção e indução, de tal modo que, além

\footnotetext{
${ }^{5}$ Art. 55. A fiscalização, no que se refere aos aspectos trabalhista, metrológico, sanitário, ambiental, de segurança e de uso e ocupação do solo das microempresas e empresas de pequeno porte deverá ter natureza prioritariamente orientadora, quando a atividade ou situação, por sua natureza, comportar grau de risco compatível com esse procedimento. [...] $\S 6^{\circ} \mathrm{A}$ inobservância do critério de dupla visita implica nulidade do auto de infração lavrado sem cumprimento ao disposto neste artigo, independentemente da natureza principal ou acessória da obrigação. § $7^{\circ}$ Os órgãos e entidades da administração pública federal, estadual, distrital e municipal deverão observar o princípio do tratamento diferenciado, simplificado e favorecido por ocasião da fixação de valores decorrentes de multas e demais sanções administrativas. $\S 8^{\circ}$ A inobservância do disposto no caput deste artigo implica atentado aos direitos e garantias legais assegurados ao exercício profissional da atividade empresarial. [...]
}

das tradicionais normas impositivas, próprias da intervenção por direção, existem, ainda, regras facultativas aos beneficiários daquele regime.

A intervenção por indução, coaduna ao estudo das normas de encorajamento feito por Norberto Bobbio (2007), pois, o modelo de Estado protetor pautado em comandos repressivos começa a ceder às técnicas de estímulo e de encorajamento. Esta função promocional do Direito

é uma alternativa à visão tradicional, de normas predominantemente sancionatórias que trazem comandos de proibição e de obrigatoriedade.

O Estado ao intervir sobre a ordem econômica por meio normativo, realiza o processo de positivação e ao indicar a propriedade como fato jurídico permite deflagrar o direito subjetivo de usar, gozar e dispor ao seu titular. Este caminho é apontado por Hernando de Soto, na obra O Mistério do Capital (2001), para incluir o potencial de ativos que permitem produzir capital e alavancar a produção, comércio, serviço, renda e 
crescimento, presentes nas relações econômicas. Para tanto é fundamental o acesso ao direito de propriedade, pois ela é a base da construção do capitalismo.

A informalidade na atividade econômica expõe a existência de um capital morto no mercado econômico, que não deve ser desconsiderado pelo Estado. Neste sentido é importante que seja estimulada a formalização por meio de mecanismos de acesso e de permanência no mercado. A LC 123/2006 é um celeiro de normas promocionais que poderão viabilizar o direito à propriedade e diminuir a exclusão daqueles que estão na extralegalidade.

Dentre as medidas de acesso ao mercado por meio de normas promocionais previstas na LC 123/2006, destacou-se a simplificação registral, que é o primeiro ato jurídico ao dar origem ao direito de propriedade empresarial. Para tanto, institui a unicidade cadastral incluindo todos os órgãos que tenham como incumbência a abertura, regularização, registros, alvarás, licenças e outras providências indispensáveis para o funcionamento regular da empresa de pequeno porte. Ainda sobre o fomento do acesso ao mercado, a LC 123/2006 trouxe o regime tributário especial do Simples Nacional, unificando a arrecadação de alguns tributos.

Já sobre as normas promocionais que prestigiam a permanência no mercado econômico, destacou-se o tratamento especial para participar nas licitações e assim realizar negócio com o poder público, preferência na contratação com empresas regionais, formação de consórcio para serviços de segurança e medicina do trabalho e simplificações de obrigações no âmbito das relações do trabalho, ainda, a dupla fiscalização.

A LC 123/06 reúne normas impositivas e promocionais que possibilitam a inclusão e permanência no domínio econômico. Alcançar estes objetivos permite o reconhecimento jurídico e social da legitimidade da intervenção do Estado, pois cria um ambiente econômico

saudável em que há respeito a livre iniciativa e livre concorrência. Neste sentido é possível um ambiente econômico em que a propriedade empresarial cumpre sua função social, portanto, apta a gerar as externalidades positivas que o capitalismo promove, também, para países em desenvolvimento tal qual o Brasil. 


\section{REFERÊNCIAS}

ALMEIDA, Amador Paes de. Comentários ao estatuto da microempresa e da empresa de pequeno porte. São Paulo: Saraiva, 2009.

BOBBIO, Norberto. Da estrutura à função: novos estudos da teoria do direito. Barueri: Manole, 2007.

BRASIL. Constituição da República Federativa do Brasil de 1988. Disponível em: <http://www.planalto.gov.br/ccivil_03/constituicao/ConstituicaoCompilado.htm>. Acesso em: 5 out. 2015.

. Lei no 10.406, de 10 de janeiro de 2002. Institui o Código Civil. Disponível em:

http://www.planalto.gov.br/ccivil_03/leis/2002/L10406compilada.htm>. Acesso em: 4 jan. 2016.

Lei Complementar $\mathbf{n}^{0}$ 123, de 14 de dezembro de 2006. Institui o Estatuto Nacional da Microempresa e da Empresa de Pequeno Porte. Disponível em: 〈http://www.planalto.gov.br/ccivil_03/leis/LCP/Lcp123.htm>. Acesso em: 4 out. 2015.

Lei complementar $n^{0}$ 147, de 7 de agosto de 2014. Altera a Lei Complementar no 123, de 14 de dezembro de 2006 [...] e dá outras providências. Disponível em: <http://www.planalto.gov.br/ccivil_03/leis/lcp/Lcp147.htm>. Acessado em: 14 dez. 2015

DERANI, Cristiane. Direito Ambiental Econômico. São Paulo: Editora Saraiva, 2008

GRAU, Eros Roberto. A ordem econômica na Constituição de 1988. São Paulo:

Editora Malheiros, 2012.

JUSTEN FILHO, Marçal. O estatuto da microempresa e as licitações públicas. 2ed. São Paulo: Dialética, 2007.

MARINS, James. BERTOLDI, Marcelo M. Simples Nacional: Estatuto Nacional da Microempresa e da Empresa de Pequeno Porte comentado. São Paulo: Editora Revista dos Tribunais, 2007.

SOTO, Hernando de. O mistério do capital. Tradução de Zaida Maldonado. Rio de Janeiro: Record, 2001. 